\title{
Effects and remedies to cultural shock on the adolescent students
}

\begin{abstract}
The adolescent students are faced with a numbers of challenges at home, school and other social cultural environment. In contemporary times little emphasis has been drawn by researchers, the academicians and scholars on challenges facing the adolescent students taking into consideration culture shock. This is due to the fact that as an adolescent move from one cultural environment to another, either one home to another or school to another, he/she often experience challenges/problem of adjusting culturally to suit the expectations of the new culture. This tends to have interplay in their academics, social, emotional, psychological, and behavioural life. It is in consonance with this fact that this paper deem it fit to investigate the effect of culture shock on the adolescent student and proffer necessary solution insight in terms of remedies. The concept of culture shock and adolescent students as used in the study were explained. Effects of cultural shock on the adolescent students were communication defectiveness, academic retardation, conflict, emotional imbalance, deviance, aloofness and withdrawal from peers; strategies identified to remedy culture shock were counseling, awareness campaign, acculturation, and co-operation. Based on the findings of the study it was recommended that there should be keen collaboration between the government, parents, school authorities and non-governmental agencies, which will help in mapping out strategies that will assist the adolescent to cope with cultural shock and make meaningful contribution financially to carry out such mandate.
\end{abstract}

Keywords: cultural shock, adolescent students, culture, adolescent
Volume 2 Issue 4 - 2018

\author{
Kingsley Akarowhe \\ Department of Educational Foundations, University of Uyo, \\ Nigeria
}

Correspondence: Kingsley Akarowhe, Department of Educational Foundations, Guidance and Counselling, Faculty of Education, University of Uyo, Nigeria, Tel +234-08I37640978, Email kingsmithII72@gmail.com

Received: May 14, 2018 | Published: August 14, 2018

\section{Introduction}

\section{Concept of cultural shock}

Culture is the summation of a group of people way of life, which often influences their relationship, behaviour, social style and belief system. It includes thoughts, styles of communicating, ways of interacting, views on roles and relationships, values, practices, and customs. ${ }^{1,2}$ Culture is formative experience of an individual. Culture has a keen role to play in every human endeavour that is it tends to set an individual different from another or a group of people from another group. Thus culture may influence a person social, emotional, behavioural, and moral life. Culture often varies from one social setting to the other and one institution to another. Shock is often used in the negative perspective in any given situation, but it is worth noting that there is a positive perspective of shock. In light of this, shock can be seen as a time frame or period from which an individual experience a negative precedent to a period of positive precedent. Similarly, shock can be defined as an unexpected or unplanned manifestation which may have either a positive or negative effect on an individual.

Culture shock was first proposed in 1958, aiming to describe the chaotic emotions of a person being in a new environment in psychology. ${ }^{3}$ Culture shock is an experience a person may have when one moves to a cultural environment which is different from one's own, it is also the personal disorientation a person may feel when experiencing an unfamiliar way of life due to immigration or a visit to a new country, a move between social environments or simply transition to another type of life. ${ }^{4}$ Cultural shock is the feeling of uncertainty, confusion or anxiety that people experience when visiting, doing business in or living in a society that is different from their own. ${ }^{5}$ Hence, culture shock has its dilemmas imbedded in a person emotional, social and behavioural life. One of the most common causes of cultural shock involves individuals in a foreign environment. ${ }^{6}$ There is no true way to entirely prevent cultural shock, as individuals in any society are personally affected by cultural contrasts differently. ${ }^{7}$

Culture shock is a common phenomenon and, through it may take months to develop; it often affects travellers and people living far from home in unexpected ways. ${ }^{8}$ According to ${ }^{5}$ cultural shock can arise from a person's unfamiliarity with local customs language and acceptable behaviour, since confusion and uncertainty sometimes with feelings of anxiety that may affect people exposed to an alien culture or environment without adequate preparation. ${ }^{8}$ Similarly, ${ }^{9}$ opined that culture shock is disorientation and frustration of those who finds themselves among people who do not share basic values and beliefs. Culture shock is the experience of frustration felt as a result of being confronted with a strange cultural phenomenon or reality which the experience finds altogether difficult and tedious to believe or accept because it sharply contradict the standard patterns of his own culture. ${ }^{10}$

\section{Meaning of adolescent student}

The term adolescent portray different understanding to different people. According to ${ }^{11}$ an adolescent is a young person who is developing from a child into adult. The adolescent is a person that range within the frame work of childhood to adulthood. In other words, an adolescent is a person that is in the developmental stage of childhood and adulthood. Due to this fact he/she often experience a particular behaviour, social, psychological and environmental disturbance or ups and downs. Adolescent is between the age of 13 and 18 year. ${ }^{11}$ It is pertinent to note that there is no general acceptable age range for an adolescent. According to ${ }^{12}$ the adolescent are excessively egoistic regarding themselves as the centre of the universe and the sole object of interest and yet at no time in later life are they capable of so much self-sacrifice and devotion.

The adolescent students are students who are in the transition 
period of childhood to adulthood. They are usually combated with different challenges and conflicts ranging from their emotional life, academic, behavioural and social among others. This is observed in their relation and adjustment strives at school and other form of social/institutional gatherings. The adolescent students are move by selfish individualized egoistic behaviours. This egoistic behaviour often helps them in portraying their superiority complex in the mix of peers, fellow students, teachers and parents. Their respective peer groups have the greatest influence on them. This is due to the fact that the adolescent student tends to conform to the norms and ethics of his/ her peer group which often protect him/her from subordinate groups.

\section{Effects of cultural shock on the adolescent students}

The following are culture shock often experience by the adolescent student.

\section{Communication defectiveness}

In every society communication is a vital means of achieving a peaceful relationship among different people/institutions within and outside a given society. In school and home communication enhance effective co-existence between student of same age bracket, parents, relation, teachers, and other children. Due to culture shock, the adolescent student tends to experience a defective communication. In other words, he/she faced with the problem of not able to relate with other adolescent students at school and at home. It is pertinent to submit that communication is an effective avenue of actualizing a given educational goal/objective in the teaching/learning processes. This is often as a result of the fact that he/she might not be able to assimilate the current culture language or mode of communication as he/she eventually find his/her self in that new locality. In the teaching and learning process in the class due to inability to utilize the present culture communication model he/she will be isolated during class discussion between fellow students and teachers. The implication of this will lead to communication gap and conflicting communication problem.

\section{Academic retardation}

A student academic is easily affected by a number of factors at home and school, but most hidden factor is culture shock. As an adolescent student move from a particular location or geographical area to another his/her academics tends to retards. This is due to the fact that it is not possible for an individual to prepare in anticipation for the new environment way of life absolutely. In other words, despite an individual longing for the new environment he/she cannot meet up with some set prior role and goals which are expected to be played and actualized. At school culture shock make the adolescent student to be dampen academically given the scenario that as students move to a new environment (school) are expected to learn new tips, make new friends, know about procedures of examination, what is often expected by the teacher in examination among others; but in the period under review the adolescent student will find it difficult to possess the needed information and skills.

\section{Conflict}

According to ${ }^{10}$ conflict is a painful condition or emotional tense state of an individual reached on account of the presence of the two equally opposed and contradictory wishes at the time. In every phase of human existence, conflict is inevitable. In other words, as an individual relates with others in the larger society conflict is bond to certainly arise. Cultural shocks also induce conflict. Conflict experience by an individual as a result of culture shock may be internal or external. Internal conflict is conflict that arose within an individual for example depression and frustration, while external conflict includes aggression towards other and isolation from friends. For an adolescent student to fully adjust or acclimatized to a new culture he/she must experience these two forms of conflict in the process of time. Due to culture shock the adolescent student may adopt aggressive tendency to the aspect of the new culture that tends to have an adverse effect on him/her. This aggressive tendency often adopted by an adolescent make him to adjust to his self determine/proposed ethics by him/her despite of the besetting conflict facing him.

\section{Emotional imbalance}

Emotional balance of an individual is an important factor that helps one to adjust meaningfully to everyday life activities. In adolescence, emotional balance is highly needed to accomplish/ acclimatize to the social environment at any given point in time. These emotional imbalances or Emotional reactions among others may include loneliness, homesickness, loss of self-confidence, mood changes, disorientation, anxiety, insecurity, depression, etc. ${ }^{13}$ Culture shock makes an adolescent to have emotional imbalance, this is as a result of ones inability to adjust meaningfully to the new culture. In other words, the adolescence is emotionally handicapped due to in ability to adjust positively to the socially accepted goals of the new culture which is often obstruct their progress. Culture shock induces an adolescent lack of tolerance and patience in relation to peers and other fellow students. This later generates to persistence depression, personality disorder, and behavioural disorder in the life of the adolescent student as a result of emotionally being imbalance in the new culture.

\section{Deviance}

Deviance is a behavioural disposition that is not in conformity with an institutionalized set-up or code of conduct. Deviance is often cause by one inability to acclimatize to the culture of a particular place. In the life of an adolescent student, deviance is often experience given the fact is a period associated with the highest behavioural, social and emotional readjustment. In the life of the adolescent students' deviance behavior often includes stealing, disobedient to constituted authority, smoking, fighting, cultism, vandalizing of school properties, illicit relationship, and looting of students fund among others. Culture shock may cause a student to adopt these deviance behaviors to cope with his/her daily life. An adolescent inadequacy to positively react to culture shock may induce him/her to be tag a deviance. In other words, due to the negative effect of culture shock an adolescent student often adopt deviance behavior in response to the new cultural domain.

\section{Aloofness and withdrawal from peers}

Aloofness and withdrawal are self-defensive mechanism that every human adopt and apply to avoid some undesirable outcome in their daily pursuit in life. In the life of an adolescent student aloofness and withdrawal is evitable. Due to the adolescent student in ability to effective comprehend, adopt, apply and utilize the new culture at home or school, he/she adopt aloofness mechanism in the group of peers. In other words, cultural shock in the life of the adolescent tend to set $\mathrm{him} /$ her apart from peers and other people at home, school and other social setting. When this persists in the life of the adolescent student he/she tend to adapt total withdrawal from any social group in the 
new cultural setting. Example of cases of aloofness and withdrawal is imbibing an unfriendly attitude, lack of commitment to group work, irritation by others people, and excommunicating peers among others. Aloofness and withdrawal is a gradual process within the time frame/ period of the effect of the culture shock on the adolescent student. If the aloofness and withdrawal induce by the culture shock in the life of the adolescent is not properly management the resultant effect is always psychological trauma.

\section{Remedies to culture shock}

Culture shock in the life of adolescent student can remedied through the following strategies.

\section{Counseling}

Counselling is a helping endeavour, in which a counselor helps a client to make positive adjustment to a given issues faced by the client, through meaningful advise from the counsellor on a particular problem he/she is facing. Counselling can help overcome personal difficulties, problems with studies but also with re-adjustment problems. ${ }^{13}$ Through counseling, a guidance counselor would be able to assist the adolescent student in remedying his/her culture shock, hence helping him/her to cope with the new culture. The adolescent student will be enlightened by the counselor on ways he/she can positively acclimatized to the new culture within and outside the school environment. The student is expected to cooperate with the counselor with the view of having insight on how to meaningfully adjust to the new culture, the counselor offer advise to the student based on received/perceived data and information. The counseling process requires a constant check-up by the counselor on the adolescent student concern. With in the process of time, the counseling process is anticipated to yield a positive outcome, by making the student to deliberately surmounting challenges posses by the new culture by adjusting meaningfully to the new culture.

\section{Awareness campaign}

Awareness campaign is an avenue of public enlightenment. It helps to reveal certain facts/information to a predetermined number of persons/people. Culture shock among adolescent can be tackled by awareness campaign. In this platform, a guidance counselor, psychiatrists, experts, and teachers through organized workshop or orientation brief or enlighten the adolescent students on a number of ways they could adjust positively to the new culture of the place one find him/her self. In such awareness programmes at school or home the adolescent student are expected to ask questions pertaining to challenges faced by them in the process of trying to adapt to the new culture they fined themselves, in turn guidance counselor, psychiatrists, experts, and teachers are expected to responds to such question which will in the long-run helps the adolescent student in positively adapting to a new culture they might find themselves. In contemporary society awareness campaign can be done through agents of communication such as the radio, internet television and social network platforms among others.

\section{Acculturation}

Acculturation is a process in which an individual adopt, acquires and adjust to a new cultural environment. It could also be seen as assimilation. According to ${ }^{10}$ acculturation is the process of acquiring or taking on by an individual or groups the culture traits of another culture. Acculturation is the adoption of new traits or patterns as a result of contact with another culture. ${ }^{7}$ Through acculturation the adolescent students learn about the new culture he/she find him/her self. According to ${ }^{13}$ the good news however is that 'culture shock' is only one phase in an on-going acculturation and learning process which eventually allows you to feel comfortable and get along in two (or more) cultures. Acculturation is a two way process. ${ }^{10}$ In acculturation the adolescent student tends to build on his/her old culture by learning the new culture. The old culture helps/aides the assimilation and association process to the new culture. In the acculturation process he/she learn the mode of greeting, the norms of the new culture, language, dressing, belief system, mode of interaction within the new culture, institutions, skills and art of the new culture. According to ${ }^{14}$ in acculturation the student may learn the new language, cultural and linguistic competence can be taught and learned and requires a commitment to individual personal growth. Although, the process is not easy-ups and downs, and the duration for an adolescent to fully adapt to the new culture varies from adolescent to adolescent. It is worthy to not that extrovert adolescent tends to adapt easily to the new culture than introvert ones.

\section{Co-operation}

Cooperation fosters a mutual relationship between different individual within a given social setting in other to achieve a particular outcome. At home, school and other social gathering cooperation is highly needed for effective synergy among different people for the purpose of attaining a set goal. Adolescence is a period of stress, which an individual tends to cooperation with others so as adjust to the socially accepted goal. As people moves from one cultural environment to another, their adjustment to the new culture is more of time frame process in other words it is not automatic. Due to this fact, cooperation with other people is an indispensable attribute to meaningfully adjust to the new culture given the time factor of association. In an adolescent life this is applicable for him/her at school, ${ }^{15}$ home and other social gathering. The adolescent must be cooperative in his/her relation with fellow students in other to fastfully acclimatize to the new culture one may find his/her self in order to overcome the defects of cultural shocks. The cooperative process for the adolescent students requires making one friendly, involving in group work, participation in class discussion, assisting fellow students, and adherence to institutionalized code of conduct. In cooperation ${ }^{14}$ attitudes change to become less ethnocentric and biased, policies change to become more flexible and culturally impartial, and practices become more congruent with the culture of the client. This will helps the adolescent student to overcome the problems of not able to adapt to the new way of life of the new environment.

\section{Conclusions and recommendation}

Cultural shock is inevitable in the life of an adolescent. Hence playing prior attention to the resultant effect and possible way to surmount the effect is very important for the adolescent student. ${ }^{16}$ The exploratory findings of this papers if proper taking into consideration by the adolescent student will pave way in remedying the resulting shock in any culture he/she may finds him/her self in the later days in life. Based on the findings of the study it was recommended that there should be keen collaboration between the government, parents, school authorities and non-governmental agencies, which will help in mapping out strategies that will assist the adolescent to cope with cultural shock and make meaningful contribution financially to carry out such mandate; Information communication technology devices 
such as radio, television, computer, internets should be adopted in the process of disseminating information that would help the adolescent students to overcome cultural shock.

\section{Acknowledgements}

None.

\section{Conflict of interest}

The author declares that there is no conflict of interest.

\section{References}

1. Robins L, Fantone J, Hermann J, et al. Improving cultural awareness and sensitivity training in medical school. Academic Medicine. 1998;73(10): S31-S34.

2. Donini Lehn off FG, Hedrick HL. Increasing awareness and implementation of cultural competence principles in health professional education. Journal of Allied Health. 2000;29(4):241-245.

3. Trompenaars F. The culture shock of mergers and acquisitions. Alexander Hughes European Newsletter. 2006;72(2):3-4.

4. Macionis J, Geber L. Culture, Sociology. 7th ed. Toronto: Pearson Canada Inc; 2010. 113 p.

5. Investopedia. Culture Shock; 2018.
6. Culture Shock; 2017

7. Barna, La Ray M. How Culture Shock Affect Communication. ERIC Communication. 2009;5(1):1-18.

8. Merriam Webster. Culture Shock. USA; 2018.

9. Broom L, Selznick D. Sociology: A Text with Adapted Readings. 7 th ed. New York: Harper and Row Publisher; 1981. 93-95 p.

10. Igbo EM. Basic Sociology. 1st ed. Enugu: CIDJAP Press; 2003. 130 p.

11. Oxford. Oxford Advance Learners Dictionary. ISE (International Student's Edition). Oxford University Press; 2010. 1796 p.

12. Blunden R. Social Development Cited Anna Freud. Springer. 1982;4:113-129.

13. Keller M. Culture Shock' How to Deal with the Challenges of Studying Abroad Student Exchange Office. Switzerland: ETH Zurich; 2014. 7 p.

14. Buttaro L. Cultural Competency: The Effects of Culture Shock and Language Stress in Health Education. International Journal of Business, Humanities and Technology. 2014;4(5):27-34.

15. Global Perspective. 4 stages of Culture Shock; 2018.

16. Mangal SK. Essentials of Educational Psychology. New Delhi: PHI Learning Private Limited; 2012. 736 p. 